\title{
In This Issue: December 2020
}

\section{Adam M. Brenner ${ }^{1}$}

Accepted: 22 October 2020 / Published online: 30 October 2020

(C) Academic Psychiatry 2020

The December 2020 issue of Academic Psychiatry includes the first print installment of our topical collection of papers on COVID-19 and Psychiatry Education, which continues to grow online [1]. These articles address the early experiences and reflections of faculty, residents, and medical students. The reader will find vivid accounts of learners, teachers, and institutions struggling to find their bearings in the face of unprecedented and sometimes overwhelming challenges. Readers will find valuable ideas about the use of new technologies and capacities of educational and clinical systems to flex and adapt under pressure.

But, as admirable as the innovations are, there is something more here. In the swirl and chaos of the pandemic, our authors reaffirm and embrace the values that are core to our professionalism. They listen to their patients and they worry about connecting with them through screens and masks. They place themselves at the frontlines of acute care and worry about the rights of patients in a public health emergency. They bear the stress of isolation and loss and see with renewed clarity the meaning of community.

The journal is grateful for the leadership of Ann Schwartz as the guest editor of the special collection. At a time when all of us were trying to figure out how to do our "day jobs" in a pandemic, Dr. Schwartz stepped forward to take on this role as well. Her steady hand as guest editor has been a very generous and timely contribution.

Guerrero et al. [2] invite us to turn our attention back to the fundamental question of "competency." The competency movement was driven by the need to define successful training as more than the completion of a set of rotations, passage through a curriculum, or length of time in apprenticeship. Their editorial and the accompanying papers are an excellent summary of the state of the art. We see educators working to define and operationalize discrete and testable tasks, including

Adam M. Brenner

adam.brenner@utsouthwestern.edu

1 University of Texas Southwestern Medical Center, Dallas, TX, USA skills that have long been part of our toolbox (formulation and supervision) as well as interventions at the cutting edge of psychiatry (neurostimulation). And even formulation, which has been taught for decades, must adapt to reflect more recent appreciation of the impact of structural determinants of mental health.

Academic Psychiatry will continue to seek out papers that define and quantify our evolving competencies, such as the paper by Rakofsky et al. [3], which describes innovative use of a simulator to teach and test psychopharmacology proficiency. At the same time, we know that we must keep an eye on the more qualitative, but equally real, skills of connection, alliance, and collaboration with patients. The paper by Balasanova et al. [4] is an excellent example of thematic analysis of student experience with a stigmatized group of patients (in this case those living with addictions). The authors contribute to the literature on how the right kind of exposure, supported by supervision and reflection, can decrease stigma.

Finally, as we bring the year to a close, we pause in this issue to appreciate our reviewers. To those of our readers who have reviewed for the journal: You are the backbone of this enterprise. You succeed in a difficult but crucial taskmaintaining rigorous scholarly standards while engaging with authors with respect and collegiality. Thank you.

And to those of our readers who have not yet reviewed for us, there is no time like the present to begin.

\section{Compliance with Ethical Standards}

Disclosures The author declares that he has no conflicts of interest.

\section{References}

1. Academic Psychiatry. COVID-19 and psychiatry education. Available at https://link.springer.com/journal/40596/ topicalCollection/AC_ab08ae134da8fbdf449373f19aec4656/page/ 1. Last accessed 21 October 2020. 
2. Guerrero APS, Aggarwal R, Balon R, et al. The competency movement in psychiatric education: 2020 view. Acad Psychiatry 2020. https://doi.org/10.1007/s40596-020-01358-y.

3. Rakofsky JJ, Talbot TB, Dunlop, BW. A virtual standardized patient-based assessment tool to evaluate psychiatric residents' psychopharmacology proficiency. Acad Psychiatry. 2020. https://doi. org/10.1007/s40596-020-01286-X.
4. Balasanova AA, MacArthur KR, DeLizza AA. "From all walks of life": attending an alcoholics anonymous meeting to reduce addiction stigma among medical students. Acad Psychiatry. 2020. https://doi. org/10.1007/s40596-020-01302-0.

Publisher's Note Springer Nature remains neutral with regard to jurisdictional claims in published maps and institutional affiliations. 